\section{Arms imports in the wake of embargoes}

\section{Vincenzo Bove iD}

University of Warwick, Coventry, UK

\section{Tobias Böhmelt}

University of Essex, Wivenhoe, UK
European Journal of International Relations $1-22$ (c) The Author(s) 2021 (c) (i) (5)

Article reuse guidelines: sagepub.com/journals-permissions DOI: I0.1 I77//354066/2II037394 journals.sagepub.com/home/ejt

@SAGE

\begin{abstract}
Do states circumvent embargoes by supplying weapons across borders to sanctioned countries? We report evidence that arms imports systematically increase in the neighborhood of conflict states under an embargo. Using several alternative researchdesign specifications, we contend that this pattern is consistent with arms exporters shifting the arms trade to neighbors of conflict states under sanctions, where it is easier to move arms clandestinely across the border. Despite the lack of direct evidence of clandestine cross-border trafficking, this research contributes to the development of more sophisticated screening tools to identify potential non-compliers with arms embargoes for direct follow-up investigations.
\end{abstract}

\title{
Keywords
}

Arms trade, conflict, counterfactual, differences-in-difference design, embargoes

\section{Introduction}

Arms imports can encourage more conflictual foreign policies or protract existing hostilities, intensify combat engagements, and are related to the outbreak of new conflicts (see e.g., Kinsella, 1994, 1998; Blanton, 1999; Craft and Smaldone, 2002; Pamp et al., 2018b; Mehrl and Thurner, 2020). Not surprisingly, in the recently launched Agenda for Disarmament, United Nations (UN) Secretary-General António Guterres highlights a direct relation between disarmament and attaining the Sustainable Development Goals

\footnotetext{
Corresponding author:

Vincenzo Bove, University of Warwick, Coventry, CV4 7AL, UK.

Email: v.bove@warwick.ac.uk
} 
(SDGs), which explicitly aim at reducing illicit arm flows (Guterres, 2018; SIPRI, 2019). Against this background, the international community and international organizations like the UN frequently impose embargoes (Brzoska, 1991, 2008; Krause, 1995), that is, restrictive measures sanctioning the supply to or receipt of specified items from a designated party to signal disapproval or to modify the behavior of the target (SIPRI, 2019). For example, one of the most recent UN embargoes was imposed on South Sudan in July 2018, prohibiting all UN members from the "direct or indirect supply, sale, or transfer to the territory of South Sudan from or through their territories [. . . ] of arms and related materiel of all types" (United Nations Security Council, 2018: 2).

Do states comply with arms embargoes? Several major arms exporters are among the most vocal supporters of multilateral humanitarian export controls. Although it may seem that there are economic incentives to do otherwise (Erickson, 2013, 2015), complying with arms embargoes does also provide material and non-material benefits. Consider, for instance, opportunities for new multilateral cooperation as well as the possibility to improve international reputation, legitimacy, and influence, which in turn likely increase compliers' military power or economic gains (Erickson, 2015; Mercer, 2010). At the same time, violations may mobilize the international community leading to "naming and shaming" which triggers a loss of legitimacy and governments' reputation in the eyes of their constituents, which is all coupled with further, potentially severe sanctions (Burgoon et al., 2015; Cortell and Davis, 2000; Erickson, 2015, 2020). Although official violations of arms embargoes are rare, and only few states are involved when violations are reported, arms control "represent[s] the quintessential collective action problem" as a large number of heterogeneous participants with difference agendas need to act (Sandler, 2000: 542). Using open-source information on official state-to-state weapon transfers, Moore (2010) documents here that arms exporting states can indeed publicly violate arms embargoes at times.

In addition to the direct supply of weapons to embargoed states, which is likely to be detected, states can also clandestinely circumvent arms restrictions by supplying arms to neighbors where the goods can then be moved more easily across the border to the sanctioned targets. For example, South Sudan's long and porous borders make it particularly difficult to control arms flows and the UN Panel of Experts on South Sudan does claim that neighboring states "likely" violated the embargo (Gibb et al., 2019). ${ }^{1}$ This case mirrors 2005, when the UN explicitly accused Rwanda and Uganda to routinely violate a 2003 arms embargo imposed on the DRC. ${ }^{2}$ Partially because of the scattered evidence, both Uganda and Rwanda have denied the allegations, as usually do countries that are accused of illegally supplying arms to embargoed targets. Are the DRC and South Sudan isolated cases? Existing reports are scant, only focusing on a handful of emblematic and often disputed episodes given the inherent difficulties in detecting countries breaching the terms of embargoes, thus accounting for a small fraction of the illegal arms trade (Bondi, 2004; DellaVigna and La Ferrara, 2010; Stohl, 2005).

This research addresses these difficulties by proposing a way to identify changes in arm trades that points toward evidence of illegal arms flows circumventing embargoes. Specifically, we focus on arms imports into countries neighboring a conflict state with an embargo. Weapons are often transferred to countries embroiled in civil conflict via thirdparty transit points (Hiscock, 2007; UNIDIR, 2006). Porous land borders, common in 
war-torn regions, and geographic proximity facilitate the transit and re-export of weapons via states neighboring a country under an embargo. As the illicit arms trade is notoriously difficult to detect and quantify, we argue that neighboring states provide ideal cases for a differences-in-differences estimator: we compare arms imports into countries neighboring conflict states (control group) with arms imports in countries that share borders with conflict countries under arms embargoes (treatment group). Assuming that, in the absence of an embargo, the units in the treatment group follow the same trend as those in the control group, the latter provides the missing potential outcome: the amount of arms imports in countries that share borders with conflict states had an arms embargo not been imposed. Detecting an increase in arms imports then highlights potential illegal weapon transfers across the border. ${ }^{3}$ Having said that, we also discuss alternative mechanisms that may well be related to this increase in arms imports and we provide indications of the presence (or absence) of some of them.

We use a comprehensive data set on all imports of major conventional weapons for 164 countries neighboring at least one other state in 1960-2018. In the appendix, we also complement these data with a largely untapped database on small arms trade. Our results provide evidence that while direct imports into sanctioned states decrease once a mandatory embargo is in place, imports into states neighboring conflict countries increase with an embargo imposed on the latter. We explore a number of alternative interpretations of our findings and also investigate the behavior of arms exporting countries. Ultimately, the increase in arms imports points toward the potential presence of illegal arms trade. Any research design, including the one we rely on here, faces difficulties in offering firm evidence of arms smuggling across borders or in detecting specific violators. However, despite a number of caveats that we discuss below, we contend that our findings are able to inform and increase the effectiveness of control, verification, and inspection systems. As such, we hope that our research offers a tool that can help raise red flags for follow-up investigations. At the same time, this work has important implications for our understanding of the international arms trade (see, e.g., Kinsella, 2011; Comola, 2012; Bove et al., 2014; Akerman and Seim, 2014; Kinne, 2016; Bove et al., 2018; Thurner et al., 2019; Blum, 2019; Mehrl and Thurner, 2020), states' compliance with arms export-control mechanisms (see, e.g., Brzoska, 1991, 2008; Moore, 2010; Erickson, 2015), and the role of international institutions in monitoring and enforcing sanctions (see, e.g., Morrow, 1994; Rosand, 2004; DeMeritt, 2012; Erickson, 2020), with likely key implications for scholars and policymakers alike.

\section{Violating arms embargoes}

The international transfer of conventional weapons between countries is one of the most dynamic sectors of cross-national trade: according to the Stockholm International Peace Research Institute Yearbook (SIPRI, 2019), the volume of international transfers of major arms between 2014 and 2018 was $7.8 \%$ higher than in 2009-2013. This is a continuation of the steady upward trend since the early $2000 \mathrm{~s} .{ }^{4}$ Yet, these figures neither include illegal transfers of major conventional weapons nor the trade of small arms and light weapons (SALW) such as machine guns and rifles, which are difficult to track (see Erickson, 2013, 2015). Simultaneously, the use and imposition of sanctions have grown over time (Figure 1), 


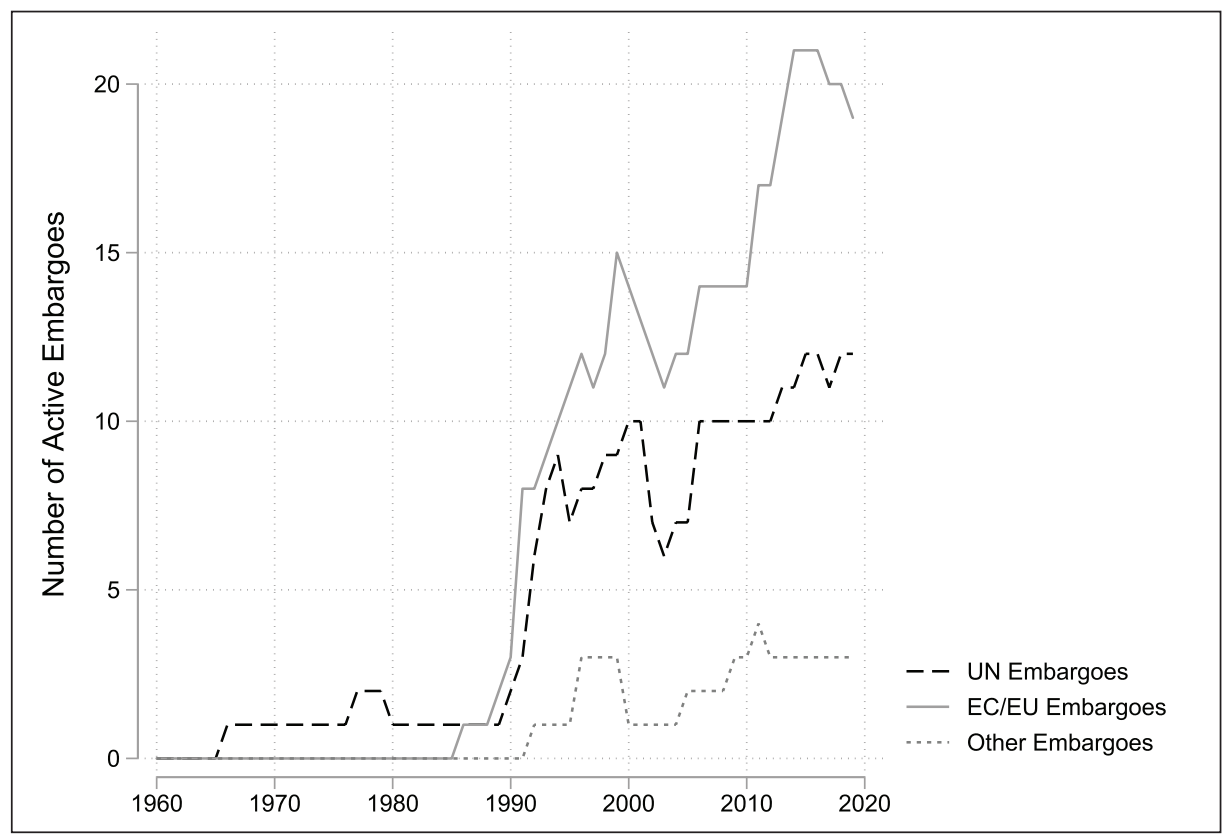

Figure I. Number of Arms Embargoes, 1960-2019.

Note: Graph shows the number of arms embargoes in force by sanctioning organization.

particularly since the end of the Cold War. According to SIPRI, a total of 34 multilateral arms embargoes were in force in 2019: 12 imposed by the UN, 19 by the EU, and three by other organizations such as the OSCE or the League of Arab States. Despite their increasing use and the evidence that they can effectively decrease arms inflows into sanctioned countries, embargoes may also be directly violated and be ineffective (as pointed to above), partially because of a poor design and a lack of enforcement and monitoring devices (e.g., Krause, 1995; Sprague, 2006; Brzoska, 2008; Moore, 2010). Embargoes do entail costs for importing and exporting states' security and military capabilities, and also impose costs on their defense industry and national economy (Smith, 2016). Hence, while arms export restrictions are formally adopted by states, breaches of these are not unheard of. Moore (2010) finds that direct, unconcealed violations of embargoes are a form of international signaling and to advance political interests. For example, during the UN embargo against Yugoslavia, both Russia and the UK supplied missiles and combat aircraft engines to the embargoed forces (Moore, 2010). And in a case study of Germany, Schulze et al. (2017) demonstrate that UN embargoes did not reduce the likelihood of arms exports to embargoed countries during the Cold War.

As Erickson (2013) points out, although sender compliance with arms embargoes is often the norm and can occur even without the threat of material punishments for violations, neither senders' compliance nor their non-compliance can be taken for granted. Compliance with arms embargoes is motivated, among others, by normative pressures and accountability at the international and domestic level, respectively. Compliance might enhance social recognition as well as the reputation of a state, which portrays itself 
as a responsible citizen of the international community on the "right side" of arms control (Erickson, 2015). This is all the more important as the "international normative environment has increasingly linked arms transfers to human rights, so too have the related standards by which states collectively judge their legitimacy and standing" (Erickson, 2015: 18). And although direct material costs can be negligible and multilateral organizations rarely have the instruments to punish violations, non-compliance with arms embargoes can generate a number of social and reputational costs. Non-governmental organizations (NGOs) can spotlight irresponsible exports in the media, shed light and scrutiny on, and publicize non-compliance (Burgoon et al., 2015; Erickson, 2020; Gleditsch et al., 2018). Calling attention to violations of international norms, particularly those involving the preservation of peace, can evoke moral reasoning and political mobilization that also awaken concern among third parties, which is heightened when international norms are domestically salient (Burgoon et al., 2015; Cortell and Davis, 2000; Erickson, 2020). For all these reasons, it is not surprising that most states, including the top arms exporters, support compliance with arms controls and there is only a limited number of official records of direct weapon transfers to embargoed targets.

Yet, whereas only few states openly violate arms embargoes, the paucity of official records on arms transfers intended purposely for the military of an embargoed target does not necessarily imply compliance with sanctions. The UN points to emblematic cases of states circumventing embargoes by clandestinely exporting arms to third-party countries (e.g., Cortright et al., 2002; UNIDIR, 2006; Hiscock, 2007; SIPRI, 2019). And Schroeder et al. (2008: 114) document several of such arms-transfer diversions, defined as the "transfer of controlled items authorized for export to one end user, but delivered to an unauthorized end user." To investigate whether weapon exports and procurement continue through clandestine routes, we focus on land neighbors of the target as borders create "structures of opportunities" (Starr and Most, 1978). Indeed, qualitative evidence suggests that crossborder trafficking is a thriving activity in many countries, particularly in the absence of border controls (see e.g., Cragin et al., 2003; Golub, 2015). What is more, several African states identify the trafficking of arms across land borders as the main type of illicit flow they are confronted with (Small Arms Survey, 2019). This is not surprising as states sharing a direct border have more interactions than distant countries, and there are more opportunities as well as incentives to engage in illegal cross-border trade.

There are at least two intertwined reasons why we may expect "special opportunities" for direct neighbors of targets in the wake of an arms embargo (Slavov, 2007). First, porous and fluid land borders give neighboring states a tangible advantage in the illegal trafficking of weapons and make them more likely to constitute an "ostensible" end-user for the transit of arms. This can allow them to trade on behalf of the target and smuggle weapons across the border to gain economic benefits. Second, neighboring states likely have vested interests in a particular outcome of a conflict in the direct proximity, often making such states to (directly or indirectly) sponsor or support one of the belligerents with the ultimate goal of acquiring resources, destabilizing a regime, or inhibiting the diffusion of conflict (Kathman, 2011; Lemke, 2002). To this end, previous research shows, for example, how sharing a border with a conflict country increases the odds of third-party military intervention (Kathman, 2011; Regan, 2002). Yet, military intervention is costly (Bove et al., 2016) and countries often resort to less invasive, cheaper forms to support the security needs of allies (Erickson, 2015). Arms transfers are one alternative form of 
assistance, which can serve to support or prevent the emergence of a group in power and promote geo-strategic and regional stability considerations (Sanjian, 1991; SIPRI, 1971). By directly (but illicitly) transferring weapons to neighbors or by serving as a transit point in a diversion scheme, neighboring states can improve the military capabilities of the recipients and secure their military advantage (Sanjian, 2003). This seems to be particularly crucial when an arms embargo is imposed against the latter, as it cripples their capacity to acquire weapons to sustain the conflict or alter the balance of power.

Weapon export and procurement can continue through clandestine routes. As of yet, however, because of the difficulties in detecting clandestine arms transfers, we have limited evidence of arms violations by nation states. As Slavov (2007: 1705) stresses, while anecdotal evidence of smuggling across the border is overwhelming, "[t]he problem with smuggling is that, by definition, it is hard to observe and quantify. Official statistics do not measure smuggling directly. One needs to think of indirect ways to infer how much smuggling is going on." As a way to infer indirectly whether illegal arms trade could be present, we investigate neighbors' weapons imports during arms embargoes: an increase here likely points toward illegal weapon transfers across the border.

\section{Main Hypothesis}

In light of this discussion, we investigate whether arms embargoes imposed on conflict countries are overcome via an increased arms trade with neighboring states. This argument leads to the theoretical expectation that in the wake of arms embargoes, states circumvent restrictions by diverting weapons to neighbors of the embargoed target.

\section{Alternative Mechanisms}

Although what happens on the border cannot be observed, we argue that, if during an arms embargo, the land neighbors start importing more weapons, we may suspect that the extra imports are intended for the target. The empirically observable implication is that arms imports should increase in states neighboring a conflict country under an embargo compared to countries bordering conflict state that does not have an embargo imposed. Yet, alternative causal mechanisms exist that could explain arms-imports increases in countries sharing borders with embargoed states. First, proximity to a country fighting a dispute may raise the probability of instability as conflict diffuses (Buhaug and Gleditsch, 2008; Gleditsch, 2007). Geographical proximity per se is sufficient to concern a state, but countries directly sharing borders with a conflict-torn nation should feel particularly threatened by the negative externalities of war. The risk of conflict spilling over to its neighbors can prompt the latter to increase their weapons imports in anticipation of such diffusion. Phillips (2015) demonstrates how concerns over conflict spill-over cause neighboring countries to increase their military spending; yet, he also shows that this happens only when the nearby civil war reaches the shared border between the countries. In the empirical analysis, we compare neighbors of countries at conflict with embargoes with neighbors of countries at conflict without embargoes as a way to mitigate concerns about arms trade as a precautionary measure in case the neighboring disputes were to expand, crossing borders in the near future. 
Second, conflict countries under embargoes may be more aggressive and engage more often in violent disputes with its neighbors. When subscribing to this pattern, neighbors simply decide to increase their defense expenditure preventively in response to such threats. Our analysis below explicitly tests for this possibility as we explore whether countries are more likely to be involved in interstate conflicts against one of their neighbors in the wake of an arms embargo. And the appendix focuses on a militarized interstate disputes. Arguably, this does not exclude the possibility that neighbors still perceive potential security threats when, for example, an embargo signals the deterioration of regional stability and potential future tensions. Nor does this rule out that exporter countries might try to stabilize neighboring countries against what they perceive as a dangerous embargoed state. While possible, this seems less likely than a reaction to the risk of geographic diffusion of civil war per se, regardless of whether or not the country in conflict is under arms embargoes. If anything, imposed embargoes should reduce the intensity of the conflict (see e.g., Hultman and Peksen, 2017).

Third, the arms trade is highly profitable to exporting countries, since it creates employment, generates income, and helps a country forge long-lasting alliances. At the same time, as national governments try to maintain their own national defense industrial bases, this support can generate large excess capacity, which makes the export market overly competitive (Smith, 2016). As demand and profits are volatile, one could think of exporters simply replacing an embargoed country with its neighbors due to excess supply. This is another plausible mechanism, although the neighboring country should be one among other arms-importing countries that receive this extra supply of arms. Our analysis is unable to detect whether a surplus of weapons actually exists in the first place, and whether these weapons are diverted toward new clients. At the same time, however, we know that sanctions can offer clear benefits to neighbors by allowing them to engage in so-called "sanctions-busting activities", that is, when they deliberately disregard sanctions that are in force against a state by trading with the embargoed target (Slavov, 2007).

In sum, two important insights follow. First, the risk of conflict spill-overs can confound the estimates of the impact of embargoes on neighbors' arms imports. Yet, we use to our advantage information on countries in conflict - with and without embargoes - and its neighbors to get as close as possible to a plausible counterfactual of what would have happened in the absence of an embargo. Second, because of the clandestine nature of cross-border trafficking, the relationship between arms imports and embargoes remains very complex. We cannot observe directly whether neighbors import weapons on behalf of the target or how much (if any) smuggling occurs. The extra arms imports of neighbors in years of enforced arms embargoes do allow for some inferences about this, however. At the same time, and perhaps more importantly, we cannot exclude that states have other strategic or economic reasons in addition to the motivations we focus on. In the conclusion, we discuss the limitations of our approach and the avenues for future research.

\section{Research design}

We have compiled a comprehensive data set covering arms imports, conflict, and embargoes in 1960-2018. The time frame covered is limited by data availability and we use data on the transfers of major conventional weapons across states from the SIPRI Arms 
Transfers Program ${ }^{5}$ as our main dependent variable. This data set is currently the most comprehensive publicly available one for bilateral arms flows for a large number of years and countries, constructed on a consistent basis. Having said that, we also show in the appendix that our results are robust when using information on (illicit) small arms trafficking. Given our research question, that is, whether states circumvent arms embargoes by diverting weapons to neighbors of embargoed targets, we focus on the behavior of national states. As such, suppliers and recipients are national governments and the country-year is the unit of analysis in this time-series cross-section data set.

In particular, we concentrate on neighboring states (or neighboring state-years) as our argument centers on the claim that, all else equal, arms imports likely increase in states neighboring a conflict country if an embargo is imposed on the latter. To this end, we concentrate on those countries that are defined as neighbors according to the Correlates of War Direct Contiguity Data Set (Stinnett et al., 2002). Initially, we employ a narrow definition of neighbors, that is, states must share a direct land or river border. After having identified pairs of neighboring countries, we compiled information on conflict activity and embargoes in those states neighboring the focal country of the monadic, country-year data set. Conflict activities are defined as by the UCDP Armed Conflict Data Set (Gleditsch et al., 2002; Pettersson et al., 2019) and we consider both interstate and intrastate conflicts (including internationalized intrastate disputes). We explain below how we use this information to create our core explanatory variable. In the appendix, we examine the robustness of our findings using different definitions of "neighbors."

The dependent variable captures a country's arms imports as defined by the SIPRI data. Our outcome variable thus focuses on the supply of military weapons through sales, aid, gifts, and those made through manufacturing licenses. ${ }^{6}$ The SIPRI data cover major conventional weapons such as aircraft, armored vehicles, artillery, radar systems, missiles, and ships designed for military use. We employ SIPRI's trend indicator values (TIVs) expressed in million US\$ at constant (1990) prices. The TIVs facilitate the comparison across different weapons. This indicator is based on the known unit production costs of a core set of weapons. Transfers of other military equipment such as small arms and light weapons are not covered. We return to this issue in the appendix, where a robustness check examines the effect of our core explanatory variables on small-arms transfers, using alternative data. We log-transform the SIPRI trend indicator after adding the value of 1 .

Data on embargoes are also from SIPRI, which maintains and continuously updates a public archive of all multilateral arms embargoes and offers background material on the political processes underpinning each embargo. ${ }^{7}$ We focus on mandatory multilateral arms embargoes that have been implemented by the UN and the EU given the scope of the empirical analysis. Note that we only include mandatory embargoes and thus exclude legally non-binding embargoes and those that are solely political commitments.

We use OLS regression and include fixed effects for countries and years next to a temporally lagged dependent variable. The latter captures unit-specific path dependencies over time as it seems plausible that past arms imports significantly inform a current year's investments. In particular, the acquisition of weaponry systems often involves long-term purchase agreements. The country fixed effects control for time-invariant 
unit-specific influences that are unobserved, while year fixed effects address concerns that arms imports may be driven by common shocks affecting all actors in the system (e.g., the end of the Cold War). This conservative setup enables accounting for the baseline level of our outcome variable and also controls for bias arising from the potential omission of unobserved characteristics.

Our core explanatory variable of interest Treatment is based on the information of countries in conflict neighboring a focal state and arms embargoes from SIPRI. We rely on the UCDP Armed Conflict Data Set (Gleditsch et al., 2002; Pettersson et al., 2019) to define conflicts, that is, interstate and intrastate ones (either with or without an international component), while the definition of neighbors is as introduced above. Specifically, Treatment receives values of either 0 or 1 , with a value of 0 standing for conflict involvement in the neighborhood (at least one neighbor involved), but no embargo is imposed on any neighbor. A value of 1 indicates that at least one embargo is imposed on a conflict state in the neighborhood of a focal country in our monadic data set. This binary setup is more conservative and, at the same time, parsimonious than a count variable, while the latter is also more likely to be contaminated by coding errors. If there is no conflict in the direct proximity of a focal state, we drop these cases from the analysis. As such, this treatment variable allows for a direct test of our hypothesis and ensures that we have a genuine differences-in-differences (DID) analysis (Abadie, 2005; Imbens and Wooldridge, 2009). That is, we thus compare arms imports over time in the treatment group (countries with conflict neighbors under embargoes) to the control group (countries with conflict neighbors without embargoes). Note that the inclusion of fixed effects for units and years is essential for the DID analysis. In the words of Angrist and Pischke (2009: 227), "group-level omitted variables can be captured by group-level fixed effects, an approach that leads to the differences-in-differences (DiD) strategy.",

Out of 3,287 observations covered by our data, 753 (22.91 percent) cases receive a value of 1 (2,534 observations are coded as 0$)$. Treatment is temporally lagged by one year. ${ }^{9}$ Figure 2 plots the mean values of our dependent variable for countries before and after the treatment occurs to allow for a visual comparison of trends. Clearly, arms imports into states neighboring a conflict country rise with arms embargoes. In the appendix, we further assess and compare the pre- and post-treatment trends in our control variables to verify the methodological assumptions (see Kahn-Lang and Lang, 2020).

The control variables, which are a standard set of "drivers" of arms imports, are also temporally lagged by one year and based on previous research on the arms trade, embargoes, and spatial influences surrounding these factors (see e.g., Levine et al., 1994; Levine and Smith, 1995, 2000; Kollias and Sirakoulis, 2002; Smith and Tasiran, 2005, 2010; Comola, 2012; Akerman and Seim, 2014; Blum, 2019). In the appendix, we show that the inclusion or exclusion of control variables does not alter the main results. Most crucially, the controls rule out that a higher amount of arms imports in a focal state is not driven by the arms embargoes in the conflict neighborhood. To this end, using the same data sources for conflict (Gleditsch et al., 2002; Pettersson et al., 2019) as above, we first consider a dichotomous variable on conflict in the country under study. A value of 1 indicates whether the focal state is in conflict ( 0 otherwise). Second, regime type is likely an important influence shaping a country's investment in 


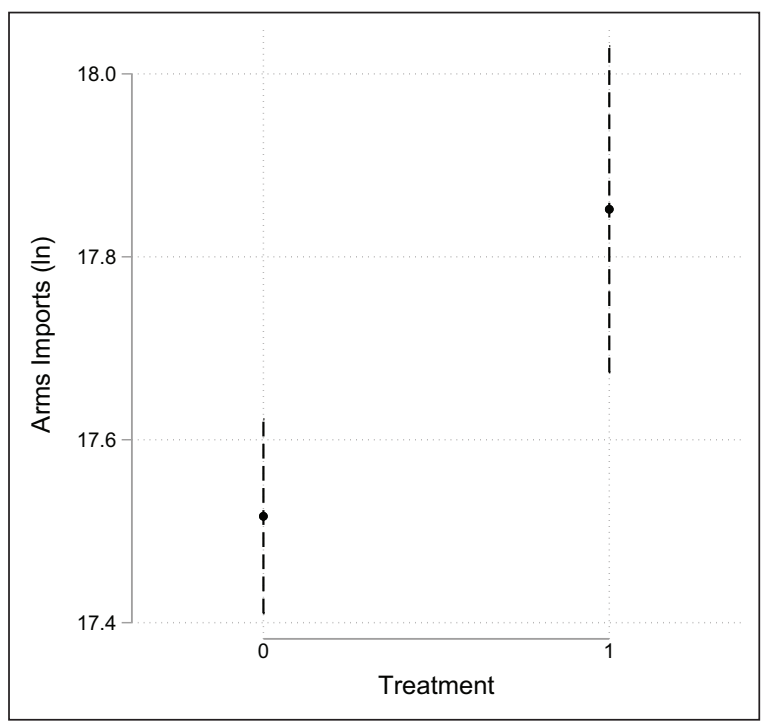

Figure 2. Arms Imports (In) by Treatment.

Note: Graph shows mean value estimates of Arms Imports (In) by Treatment. Dashed lines signify 90 percent confidence interval.

arms. Using the polity2 indicator from the Polity IV project, we created a binary variable that receives a value of 1 if the polity 2 score is 7 or higher on the $[-10 ; 10]$ interval. Values below 7 receive a value of 0 . Third, another binary item captures membership in the North Atlantic Treaty Organization (NATO). We created this variable using information from the organization's website. Finally, employing the World Bank Development Indicators, we consider three controls that capture standard socio-economic influences. On one hand, there are a focal country's GDP and population. Both items are log-transformed. Economically more powerful and larger states, all else equal, invest more in arms than economically weaker and smaller countries. On the other hand, we include trade openness, that is, trade as percentage of GDP, to control for the overall embeddedness of a country in the world's economic network. We also log-transform this last control. Table 1 summarizes the descriptive statistics of all variables discussed so far.

\section{Empirical results}

We summarize the main models in Table 2. Model 1 is a "standard model" of arms imports, leaving out our core variable of interest. To facilitate comparison, we rely on the same, reduced sample as in Model 2. In essence, this baseline estimation shows that opportunity and path dependency crucially shape the inflow of arms: GDP (ln) and the lagged dependent variable are statistically significant and positively signed, suggesting that arms imports in the year before are positively related to arms imports in the current year and that more economically powerful countries invest more in arms imports as they 
Table I. Descriptive Statistics.

\begin{tabular}{lrlrrr}
\hline Variable & Mean & Std. Dev. & Min. & Max. & Obs. \\
\hline Arms Imports $(\ln )$ & 17.421 & 3.421 & 0.000 & 22.439 & 5,364 \\
Lagged Dependent Variable & 17.828 & 3.046 & 0.000 & 22.439 & 4,632 \\
Treatment & 0.229 & 0.420 & 0.000 & 1.000 & 3,287 \\
War & 0.326 & 0.469 & 0.000 & 1.000 & 5,364 \\
Democracy & 0.368 & 0.482 & 0.000 & 1.000 & 5,313 \\
NATO & 0.166 & 0.372 & 0.000 & 1.000 & 5,364 \\
GDP $(\operatorname{In})$ & 24.016 & 2.222 & 17.419 & 30.601 & 4,784 \\
Population $(\operatorname{In})$ & 16.289 & 1.522 & 11.942 & 21.050 & 5,272 \\
Trade Openness $(\operatorname{In})$ & 4.033 & 0.681 & -1.787 & 6.081 & 4,561 \\
\hline
\end{tabular}

Table 2. Arms Imports in the Wake of Embargoes.

\begin{tabular}{lcc}
\hline & Model I & Model 2 \\
\hline Lagged Dependent Variable & $0.296^{* * *}$ & $0.293^{* * *}$ \\
& $(0.020)$ & $(0.020)$ \\
Treatment & & $0.546^{* * *}$ \\
War & & $(0.138)$ \\
& $0.207^{*}$ & $0.194^{*}$ \\
Democracy & $(0.106)$ & $(0.106)$ \\
& 0.127 & 0.156 \\
NATO & $(0.150)$ & $(0.149)$ \\
& 0.271 & 0.294 \\
GDP $($ In) & $(0.350)$ & $(0.349)$ \\
& $0.905^{* * *}$ & $0.883^{* * *}$ \\
Population $($ In) & $(0.137)$ & $(0.137)$ \\
& 0.413 & 0.119 \\
Trade Openness (In) & $(0.340)$ & $(0.347)$ \\
& $0.255^{*}$ & 0.167 \\
Constant & $(0.130)$ & $(0.131)$ \\
& $-15.028^{* *}$ & -9.390 \\
Observations & $(6.287)$ & $(6.428)$ \\
Country Fixed Effects & 2,549 & 2,549 \\
Year Fixed Effects & Yes & Yes \\
Prob. $>$ F & Yes & Yes \\
\hline & 0.000 & 0.000 \\
\hline
\end{tabular}

Standard errors in parentheses; ${ }^{*} p<0.10,{ }^{* *} p<0.05,{ }^{* * * *} p<0.01$.

have the means to do so. These two findings are consistent across all model estimations presented here and in the appendix. However, note that our estimates are rather conservative and the combination of a lagged level of arms imports with country-specific and year fixed effects absorbs a lot of variation. This induces that most of the control variables are insignificant at conventional levels. 
Model 2 then additionally incorporates Treatment, which takes on the value 0 when there is at least one conflict in the neighborhood, but no embargoes are in place; and a value of 1 is assigned if at least one embargo is imposed on a conflict state in the neighborhood. In other words, we only consider countries with conflict in the neighborhood in a DID setup (hence, the drop in the number of observations), calculated as the change in arms imports in countries sharing a border with a conflict state before and after an embargo is imposed relative to the change in the "non-embargo areas." As expected, Treatment is positively signed, significant at the 1 percent level, and emphasizes that there is a meaningful increase in arms imports occurring in treated countries. Given the log-linearity of the model, the interpretation of the coefficient is that of a proportional change in the arms imports given a unit change in Treatment, holding all else constant. Therefore, moving from 0 to 1 for Treatment translates into an increase of more than 70 percent in arms imports of the focal state. ${ }^{10}$ As such, the substantive effects are not only statistically significant, but also economically meaningful. Figure 3 graphically presents the linear predictions of Arms Imports $(\ln )$ for the different values of Treatment and Figure 4 simulates the coefficient of Treatment following King et al. (2000). On one hand, moving from 0 to 1 on Treatment, the linear prediction of Arms Imports (ln) changes from about 17.9 to more than 18.4. Mirroring what we present in Table 2, this change is significant as the point estimates' confidence intervals do not overlap. On the other hand, simulating the coefficient of Treatment in Figure 4, the mean effect is close to the coefficient estimate from Model 2 (0.546) above, albeit slightly smaller (0.533). Most importantly, none of the simulated coefficient values overlaps with 0 . In the appendix, we show that a one-unit change in the treatment is estimated to increase arms imports by similar volumes across several models and specifications.

We also evaluate additional evidence for the reported results. First, the empirical analysis must rule out selection bias resulting from any differences in pre-embargo trends. Following Kahn-Lang and Lang (2020: 619), the appendix explores "what factors might explain the differences in levels in the period prior to treatment." We report some differences across treatment and control groups in terms of several factors and we address this issue by interactions between the "problematic" predictors and time period. As emphasized in Kahn-Lang and Lang (2020: 619), "[i]f this substantively changes the interpretation of treatment effects, this should raise serious concerns about our estimates of the treatment effect." However, as we demonstrate, this does not apply in our case.

Second, as discussed above, arms diversion may not be the only possible interpretation of our results, however. That is, countries could feel threatened by a war-torn neighboring state after an embargo has been imposed against it as conflict might be more likely to cross the border under the new circumstances. This would result in a higher demand for arms in preparation for fighting. Table 3 investigates this possibility explicitly as we explore whether countries are more likely to be involved in a militarized interstate dispute in the wake of an arms embargo against one of their neighbors (as defined by Treatment). The dependent variable used for the analysis in Table 3 is binary and taken again from the UCDP (Gleditsch et al., 2002; Pettersson et al., 2019), but we now focus on interstate conflict only. Out of 2,645 observations in our sample, after accounting for missing values, 110 of them (4.16 percent) have seen such disputes. Next to the controls we rely on above, we consider an item on military expenditure taken from the 


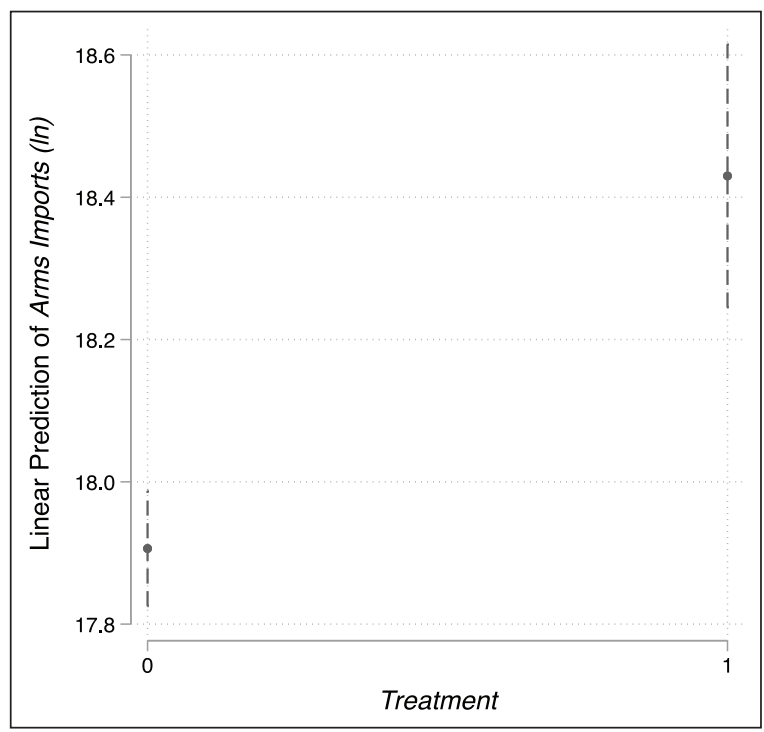

Figure 3. Linear Prediction of Arms Imports (In).

Note: Dashed lines signify 90 percent confidence interval. Calculations based on Model 2, while holding all variables except for Treatment constant at their means.

World Bank Development Indicators, while the main focus is on the effect of Treatment, which captures whether at least one neighbor in conflict is under an embargo. We use a linear probability model with country fixed effects to facilitate the direct interpretation of the coefficients, but the results are similar when using logistic regression. Temporal correlation is accounted for by a temporally lagged dependent variable and fixed effects for years. Table 3 highlights that countries with embargoed states in the neighborhood are not more or less likely to become involved in interstate disputes. Having said that, note that this test does not rule out the possibility that states feel threatened by regional instabilities. In fact, estimating the prospective that a country will become involved in a dispute or any violent incident as a result of arms embargoes is difficult ex-ante.

Third, if our mechanism holds, we should find some evidence of a diversion of arms transfers of one exporter away from the embargoed target and toward a neighbor. Whereas multiple transit points are often used in a diversion scheme, and thus neighboring countries are only the final destination through a long transfer chain comprising several intermediaries, it is sometimes the case that only one declared recipient - as opposed to the actual recipient - is involved in the transaction (Schroeder et al., 2008). To test this, we created a data set on weapon exporters, conflict states (with and without embargoes), and their neighbors. In other words, we use a $k$-adic analysis (Poast, 2010) where the unit of analysis now is the exporter-importer-neighbor year to examine more carefully the trade-off in the arms trade and how trade exports are being re-directed in the wake of embargoes. We employ 3SLS regression for this, which combines seeminglyunrelated regression (SUR) with two-stage least squares estimation (2SLS). That is, 


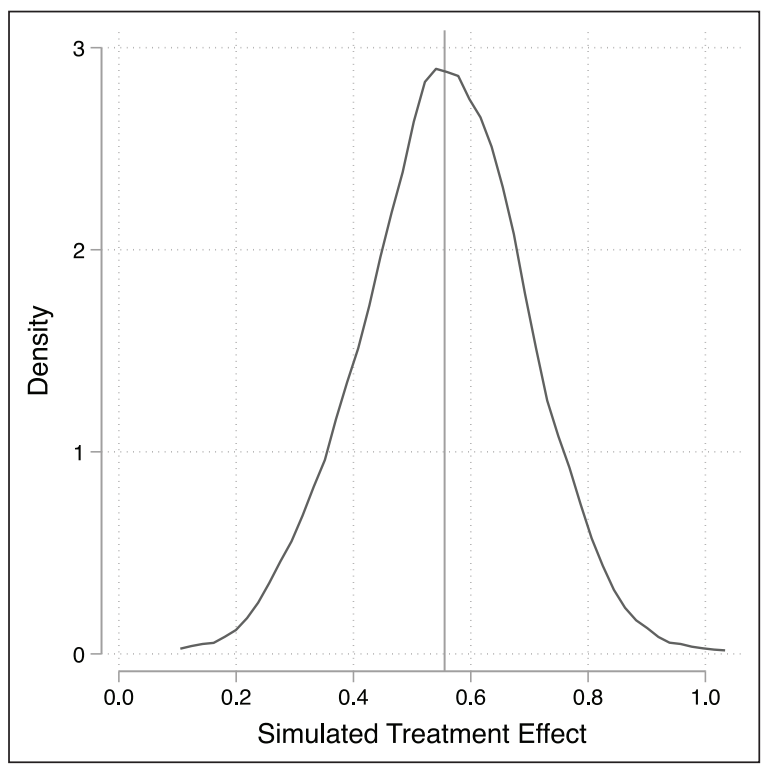

Figure 4. Simulated Treatment Effect.

Note: Graph shows simulated coefficient estimates of Treatment, while holding all other covariates constant at their means. Estimates are based on simulations $(N=1,000$ draws of simulated parameter from multivariate normal distribution). Solid vertical line marks mean value of simulated coefficients $(0.533)$.

3SLS is suitable in a system of equations that are endogenous, i.e., in each equation there are endogenous variables on both the left and right-hand sides of the equation. This is the 2SLS component. On the other hand, 3SLS directly takes into account that the error terms in each equation are correlated, which is the SUR element. The combination of these two components is the key strength of 3SLS (see Bakaki et al., 2020).

We specify two equations to this end: one that has the arms exports to the neighbor as the dependent variable, a second focuses on the arms exports to the focal country in conflict. In both equations, the exporting country is identical and we include fixed effects for focal states or neighbors, the (potential) exporting country shipping weapons into the focal country and/or one of its neighbors, and years. We omit the control variables used above, since they are neither consistently related to any of the outcome variables we employ nor do we achieve convergence with the 3SLS approach when including all of them at the same time. The core aspect of this setup is an interaction between a variable capturing whether there is an embargo in a conflict country and an item on the arms exports to the state in conflict, which we include as predictors in the equation pertaining to the neighboring country and, thus, treat as endogenous variables. We feed them into 3SLS in the following three steps: all exogenous variables in the system are used to create the instrumented values of the endogenous items. Second, 3SLS estimates a crossequation covariance matrix. Third, we calculate the simultaneous equations via generalized least squares, employing the instrumented variables and the exogenous items as well as the estimated covariance matrix. Table 4 summarizes our findings. 
Table 3. Embargoes and a Higher Risk of Interstate War?.

\begin{tabular}{lc}
\hline & Model 3 \\
\hline Lagged Dependent Variable & $0.326^{* * *}$ \\
Treatment & $(0.018)$ \\
Democracy & -0.011 \\
& $(0.011)$ \\
NATO & 0.003 \\
& $(0.012)$ \\
GDP (In) & 0.006 \\
& $(0.027)$ \\
Population (In) & $0.024^{* *}$ \\
Trade Openness (In) & $(0.012)$ \\
& 0.013 \\
Military Expenditure (In) & $(0.030)$ \\
& -0.009 \\
Constant & $(0.013)$ \\
Observations & $0.026^{*}$ \\
Country Fixed Effects & $(0.014)$ \\
Year Fixed Effects & $-0.904^{*}$ \\
Prob. $>$ F & $(0.542)$ \\
\hline
\end{tabular}

Standard errors in parentheses; $* p<0.10,{ }^{* *} p<0.05$, *** $p<0.01$.

As shown there, arms flows into a state under an embargo decrease from a specific exporter, which seems to suggest that the latter complies, at least partially, with the imposed sanctions. Put differently, embargoes are effective as they lower the direct arms trade into embargoed targets. However, the exact same exporter increases weapon sales to the conflict countries' neighboring states. The interaction term highlights this as the negative sign demonstrates that arms imports into a neighboring country increase when the weapons trade with the conflict state under an embargo decreases. And the latter is given from the first equation in Table 4. In sum, and linking these results back to our argument, we find coherent and consistent evidence that the arms trade is redirected in the face of embargoes. Embargoes do have an impact on arms imports as they lead to lower arms inflows into embargoed countries in general, but this occurs at the advantage of the arms trade into the neighborhood. This is precisely what we show here, building on the identification strategy following a DID design. Hence, we can point to the observable implication of our theory, namely that arms imports increase in light of conflict and embargoes in the neighborhood. We can also highlight that this is driven by embargoes as such. Still, we cannot offer firm evidence of the presence of arms smuggling and armstransfer diversions, which should be the aim of carefully designed case studies. 
Table 4. 3SLS Regression Model: A Trade-Off in Arms Trade?.

\begin{tabular}{lccc}
\hline & Model 4 & Model 4 \\
\cline { 2 - 3 } & State in Conflict & & Neighbor \\
\hline Lagged Dependent Variable & $0.566^{* * * *}$ & $0.560^{* * * *}$ \\
Embargo in State in Conflict & $(0.002)$ & $(0.002)$ \\
& $-0.024^{* * * *}$ & $0.034^{* * *}$ \\
Arms Exports to State in Conflict & $(0.009)$ & $(0.008)$ \\
& & $0.047^{* * * *}$ \\
Embargo in State in Conflict $\times$ & & $(0.003)$ \\
Arms Exports to State in Conflict & & $-0.022^{* * *}$ \\
Constant & $1.001 * * *$ & $(0.005)$ \\
& $(0.036)$ & $0.969 * * *$ \\
Observations & 304,006 & $(0.036)$ \\
Country Fixed Effects & Yes & 304,006 \\
Year Fixed Effects & Yes & Yes \\
\hline
\end{tabular}

Standard errors in parentheses; $* p<0.10, * * p<0.05, * * * p<0.01$.

The appendix summarizes a variety of alternative specifications to further increase the confidence in our results. First, we omit all control variables and show that the inclusion or exclusion of variables does not alter the main variable's impact qualitatively. Second, embargoes may also be imposed on focal states and we show that dropping these from the analysis does not change our results substantively. Third, we present the results when using a different estimator, when employing random instead of fixed effects, when relying on bootstrapped standard errors, and when leaving the lagged dependent variable out of the main model. Fourth, currently, all explanatory variables are lagged by one year, but focusing on variable values of the same year does not have an impact on our substantive findings. Fifth, and this is also theoretically important, we use alternative data for our dependent variable: while the SIPRI data focus on major arms and weapons, the appendix comprises an analysis based on the frequency of small-arms deals. Sixth, we have disaggregated embargoes by source (EU vs. UN). Seventh, we demonstrate the effect of external support for a state under embargo and we conduct a placebo test: rather than focusing on conflict states with embargoes in the neighborhood, we concentrate on non-conflict states with embargoes in close proximity. Eighth, we summarize the findings from a post-1990 sample analysis and we vary the definition of neighbors and proximity. Ninth, there is an examination of the differences across the treatment and control groups and we look at the temporal persistence of embargo effects. Tenth, we employ alternative data for a replication of Table 3 above. Overall, our previous expectations about the effect of embargoes on arms imports are strongly borne out by all these additional empirical results. Finally, in the last models in the appendix we also seek to identify some scope conditions. On the one hand, as violating embargoes is costly and tied to potential political and economic actions by the international community, neighboring states' standing in the international community should matter. We find that the higher the 
political, economic, and social standing worldwide, the lower our treatment effect. On the other hand, we consider embargoed countries' relationship with importing states as the quality of this relationship could moderate the estimated effect. We find that only when relations are not-hostile there is evidence that neighbors might help circumvent arms embargoes.

\section{Conclusion}

States' formal commitment to arms export restrictions entails a number of benefits, such as improving their reputation as responsible and trustworthy citizens in the international arena and enhancing the opportunities for collaboration. And despite the absence of much of an enforcement capacity or a binding accountability mechanism in most embargoes, non-compliance with such instruments can carry long-lasting reputational damages. At the same time, the practical implementation of more restrictive arms-transfer standards entails economic and strategic costs, whereas clandestine violations are likely to go undetected and unpunished.

In this article, we investigate whether countries divert weapons to neighbors of embargoed targets. Anecdotal evidence suggests that neighboring countries violate arms embargoes by supplying arms through clandestine routes. As such, we cannot establish illegal arms transactions by using official data on bilateral flows of weapons. At the same time, first-hand information on arms seizures and illegal weapons shipments are scattered or incomplete and represent a few emblematic cases with a lot of media attention. Our indirect identification strategy tests the expectation that arms embargoes in one state will increase the weapons trade into neighboring states. That is, we assembled data on arms transfers and use a DID estimator by comparing the evolution of arms imports before and after an embargo is imposed in areas "exposed to the treatment" as compared to those that were not.

We find a systematic increase in arms imports in states neighboring conflict countries under embargo. As other mechanisms could be at play, we evaluate a (non-exhaustive) number of alternative explanations. Eventually, the increase we observe in the import of arms is consistent with the presence of an arms diversion mechanism, although we cannot rule out the existence of additional, underlying mechanisms. Whereas we only provide indirect evidence, and several caveats are discussed below, our approach can be used to help raise red flags for identifying potential targets of investigation. This work sheds also light on the actual effectiveness of important international agreements and we provide a useful framework to understand under which circumstances clandestine violations are more likely to be observed.

Our findings have three limitations that could stimulate future research. First, effective sanctions are unobservable as they are often never really imposed, particularly when states vulnerable to sanctions are deterred from misbehaving (Drezner, 2003; Miller, 2014). In fact, the relationship between importers and exporters is one important limitation to the pursuit of costly norm enforcement (Erickson, 2020). Yet, some costly embargoes are actually imposed, otherwise there would be no evidence of arms diversion. That said, given the existence of selection processes that can determine the target and type of sanctions, future analyses should mitigate selection bias by coding the instances in which 
the threat of coercion did not have to be carried out and model the selection of targets given the multiple relations they have with senders. Second, our study only glances at the edges of which actors have more incentives to violate arms embargoes. For one, we are unable to say whether neighboring countries directly (but secretively and illicitly) supply their own weapons to conflict parties or if they act as intermediaries in a larger diversion scheme. What is more, we do not know which share of arms exports to neighboring countries actually cross the border. Our findings pertain to an average effect across countries and do not imply that all (or most) neighboring countries violate embargoes.

We do point out to an important pattern, though - arms imports systematically increase in the neighborhood of conflict countries under an embargo, - but the intent of arms diversion and the nature of the collusion need to be further investigated, using in-depth case studies if possible. We hope that this research can encourage the development of more sophisticated screening tools to identify potential non-compliers with arms embargoes and export restrictions for more thorough investigations. Furthermore, as systemic arms embargo violations are even less likely to be detected when small arms and light weapons, as opposed to major conventional weapons, are trafficked, the collection of more comprehensive data on small and light arms transfers, which is fraught with enormous difficulties, should be encouraged.

\section{Funding}

The author(s) received no financial support for the research, authorship, and/or publication of this article.

\section{ORCID iDs}

Vincenzo Bove (iD https://orcid.org/0000-0001-7398-9049

Tobias Böhmelt iD https://orcid.org/0000-0002-7661-8670

\section{Supplemental material}

Supplemental material for this article is available online.

\section{Notes}

1. See online at: https://tinyurl.com/ybs6t63d.

2. See online at: https://tinyurl.com/yc4tvmzc.

3. Using information on arms-producing companies and event data for eight countries under UN arms embargoes between 1990 and 2005, DellaVigna and La Ferrara (2010) detect illegal arms transactions based on daily stock returns.

4. For an overview of the factors shaping the supply and demand for arms, see, e.g., Levine et al. (1994), Levine and Smith (2000), Smith and Tasiran (2005), Kinsella (2011), Comola (2012), Bove et al. (2018), Pamp et al. (2018a) and Blum (2019). Network-oriented explanations of the arms trade and weapons agreements are offered by Akerman and Seim (2014), Kinne (2016), or Thurner et al. (2019).

5. Available online at: www.sipri.org/databases/armstransfers.

6. It is not unusual that arms are being transferred for free to allies, under the umbrella of military aid. SIPRI data are based on the known unit production costs of a core set of weapons and they are appropriate to test our argument as we require data on the volume of military resources rather than the financial value or contracted prices of the transfer, which is 0 in presence of military aid. 
7. Available online at: https://www.sipri.org/databases/embargoes.

8. For a recent similar application and setup as ours, see Gizelis and Cao (2021) whose paneldata differences-in-differences estimation also comprises fixed effects for units and years next to the treatment indicator.

9. As the data on arms trade are annual, a year in which an arms embargo is only partially in place could in principle allow for legal transfers. Moreover, it may take a few months for countries to comply with new restrictions.

10. For $\beta=0.546, e^{0.546} \approx 1.70$, i.e., a one-unit change in the explanatory variable corresponds to (approximately) an expected increase in the outcome of 70 percent.

\section{References}

Abadie A (2005) Semiparametric difference-in-differences estimators. Review of Economic Studies 72(1): 1-19.

Akerman A and Seim AL (2014) The global arms trade network 1950-2007. Journal of Comparative Economics 42(3): 535-551.

Angrist JD and Pischke J-S (2009) Mostly Harmless Econometrics: An Empiricist's Companion. Princeton, NJ: Princeton University Press.

Bakaki Z, Böhmelt T and Ward H (2020) The triangular relationship between public concern for environmental issues, policy output, and media attention. Environmental Politics 29(7): $1157-1177$.

Blanton SL (1999) Instruments of security or tools of repression? Arms imports and human rights conditions in developing countries. Journal of Peace Research 36(2): 233-244.

Blum J (2019) Arms production, national defense spending, and arms trade: Examining supply and demand. European Journal of Political Economy 60(1): 101814.

Bondi L (2004) Externalities of the arms trade. In Passas N and Goodwin N (eds), It's Legal but It Ain't Right, Ann Arbor, IL: University of Michigan Press, 43-73.

Bove V, Elia L and Sekeris PG (2014) US security strategy and the gains from bilateral trade. Review of International Economics 22(5): 863-885.

Bove V, Gleditsch KS and Sekeris PG (2016) 'Oil Above Water'? Economic interdependence and third-party intervention. Journal of Conflict Resolution 60(7): 1251-1277.

Bove V, Deiana C and Nisticò R (2018) Global arms trade and oil dependence. Journal of Law, Economics, and Organization 34(2): 272-299.

Brzoska M (1991) Arming South Africa in the shadow of the un arms embargo. Defense Analysis $7(1): 21-38$.

Brzoska M (2008) Measuring the effectiveness of arms embargoes. Peace Economics, Peace Science, and Public Policy 14(2): 2-2.

Buhaug H and Gleditsch KS (2008) Contagion or confusion? Why conflicts cluster in space. International Studies Quarterly 52(2): 215-233.

Burgoon B, Ruggeri A, Schudel W, et al. (2015) From media attention to negotiated peace: human rights reporting and civil war duration. International Interactions 41(2): 226-255.

Comola M (2012) Democracies, politics, and arms supply. Review of International Economics 20(1): $150-163$.

Cortell AP and Davis JW (2000) Understanding the domestic impact of international norms: a research agenda. International Studies Review 2(1): 65-87.

Cortright D, Lopez GA, Lopez GA, et al. (2002) Sanctions and the Search for Security: Challenges to UN Action. London: Lynne Rienner Publishers.

Craft C and Smaldone JP (2002) The arms trade and the incidence of political violence in SubSaharan Africa, 1967-97. Journal of Peace Research 39(6): 693-710. 
Cragin K, Hoffman B, Berends M, et al. (2003) Arms Trafficking and Colombia. Los Angeles, CA: Rand Corporation.

DellaVigna S and La Ferrara E (2010) Detecting illegal arms trade. American Economic Journal: Economic Policy 2(4): 26-57.

DeMeritt J (2012) International organizations and government killing: does naming and shaming save lives? International Interactions 38(5): 597-621.

Drezner DW (2003) The hidden hand of economic coercion. International Organization 57(3): 643-659.

Erickson J (2015) Dangerous Trade: Arms Exports, Human Rights, and International Reputation. New York: Columbia University Press.

Erickson JL (2013) Stopping the legal flow of weapons: compliance with arms embargoes, 19812004. Journal of Peace Research 50(2): 159-174.

Erickson JL (2020) Punishing the violators? Arms embargoes and economic sanctions as tools of norm enforcement. Review of International Studies 46(1): 96-120.

Gibb M, Gillespie D, Kolmakov A, et al. (2019) Letter dated 9 April 2019 from the panel of experts on south Sudan addressed to the president of the security council. United Nations Security Council (S/2019/301).

Gizelis T-I and Cao X (2021) A security dividend: peacekeeping and maternal health outcomes and access. Journal of Peace Research. Forthcoming.

Gleditsch KS (2007) Transnational dimensions of civil war. Journal of peace research 44(3): 293-309.

Gleditsch KS, Hug S, Schubiger LI, et al. (2018) International conventions and nonstate actors: selection, signaling, and reputation effects. Journal of Conflict Resolution 62(2): 346-380.

Gleditsch NP, Wallensteen P, Eriksson M, et al. (2002) Armed conflict 1946-2001: a new dataset. Journal of Peace Research 39(5): 615-637.

Golub S (2015) Informal cross-border trade and smuggling in Africa. In Handbook on Trade and Development. London: Edward Elgar Publishing.

Guterres A (2018) Remarks at the University of Geneva on the Launch of the Disarmament Agenda. New York: United Nations.

Hiscock D (2007) Beyond the Reach of State Monopoly Controls: A Comparative Overview of Russian Controls on Arms Brokering. London: Saferworld.

Hultman L and Peksen D (2017) Successful or counterproductive coercion? the effect of international sanctions on conflict intensity. Journal of Conflict Resolution 61(6): 1315-1339.

Imbens GW and Wooldridge JM (2009) Recent developments in the econometrics of program evaluation. Journal of Economic Literature 47(1): 5-86.

Kahn-Lang A and Lang K (2020) The promise and pitfalls of differences-in-differences: reflections on 16 and pregnant and other applications. Journal of Business \& Economic Statistics 38(3): 613-620.

Kathman JD (2011) Civil war diffusion and regional motivations for intervention. Journal of Conflict Resolution 55(6): 847-876.

King G, Tomz M and Wittenberg J (2000) Making the most of statistical analyses: improving interpretation and presentation. American Journal of Political Science 44(2): 347-361.

Kinne BJ (2016) Agreeing to arm: bilateral weapons agreements and the global arms trade. Journal of Peace Research 53(3): 359-377.

Kinsella D (1994) Conflict in context: arms transfers and third world rivalries during the cold war. American Journal of Political Science 38(3): 557-581.

Kinsella D (1998) Arms transfer dependence and foreign policy conflict. Journal of Peace Research 35(1): 7-23. 
Kinsella D (2011) The arms trade. In Coyne C and Mathers R (eds), Handbook on the Political Economy of War. London: Edward Elgar, 217-242.

Kollias C and Sirakoulis K (2002) Arms racing and the costs of arms imports: a stochastic model. Defence and Peace Economics 13(2): 137-143.

Krause K (1995) Arms and the State: Patterns of Military Production and Trade. Number 22. Cambridge: Cambridge University Press.

Lemke D (2002) Regions of War and Peace. Cambridge: Cambridge University Press.

Levine P and Smith R (1995) The arms trade and arms control. Economic Journal 105(429): 471-484.

Levine P and Smith R (2000) The arms trade game: from laissex-faire to a common defence policy. Oxford Economic Papers 52(2): 357-380.

Levine P, Sen S and Smith R (1994) A model of the international arms market. Defence and Peace Economics 5(1): 1-18.

Mehrl M and Thurner PW (2020) Military technology and human loss in intrastate conflict: the conditional impact of arms imports. Journal of Conflict Resolution. Forthcoming.

Mercer J (2010) Reputation and International Politics. Ithaca, NY: Cornell University Press.

Miller NL (2014) The secret success of nonproliferation sanctions. International Organization 68(4): 913-944.

Moore M (2010) Arming the embargoed: a supply-side understanding of arms embargo violations. Journal of Conflict Resolution 54(4): 593-615.

Morrow JD (1994) Modeling the forms of international cooperation: distribution versus information. International Organization 48(3): 387-423.

Pamp O, Dendorfer F and Thurner PW (2018a) Arm your friends and save on defense? The impact of arms exports on military expenditures. Public Choice 177(1-2): 165-187.

Pamp O, Rudolph L, Thurner PW, et al. (2018b) The build-up of coercive capacities: arms imports and the outbreak of violent intrastate conflicts. Journal of Peace Research 55(4): 430-444.

Pettersson T, Högbladh S and Öberg M (2019) Organized violence, 1989-2018 and peace agreements. Journal of Peace Research 56(4): 589-603.

Phillips BJ (2015) Civil war, spillover and neighbors? Military spending. Conflict Management and Peace Science 32(4): 425-442.

Poast P (2010) (mis) using dyadic data to analyze multilateral events. Political Analysis 18(4): 403-425.

Regan PM (2002) Civil Wars and Foreign Powers: Outside Intervention in Intrastate Conflict. Ann Arbor, IL: University of Michigan Press.

Rosand E (2004) The security council's efforts to monitor the implementation of al qaeda / taliban sanctions. American Journal of International Law 98(4): 745-763.

Sandler T (2000) Arms trade, arms control, and security: collective action issues. Defence and Peace Economics 11(3): 533-548.

Sanjian GS (1991) Great power arms transfers: modeling the decision-making processes of hegemonic, industrial, and restrictive exporters. International Studies Quarterly 35(2): 173-193.

Sanjian GS (2003) Arms transfers, military balances, and interstate relations: modeling power balance versus power transition linkages. Journal of Conflict Resolution 47(6): 711-727.

Schroeder M, Close H and Stevenson C (2008) Deadly deception: arms transfer diversion. In Small Arms Survey 2008: Risk and Resilience. Cambridge: Cambridge University Press, 112-153.

Schulze C, Pamp O and Thurner PW (2017) Economic incentives and the effectiveness of nonproliferation norms: German major conventional arms transfers 1953-2013. International Studies Quarterly 61(3): 529-543.

SIPRI (1971) Arms Trade Registers: The Arms Trade with the Third World. Stockholm International Peace Research Institute. Stockholm: Almqvist and Wiksell. 
SIPRI (2019) SIPRI Yearbook 2019: Armaments, Disarmament, and International Security. Oxford: Oxford University Press.

Slavov ST (2007) Innocent or not-so-innocent bystanders: evidence from the gravity model of international trade about the effects of un sanctions on neighbour countries. World Economy 30(11): 1701-1725.

Small Arms Survey (2019) Weapons Compass: Mapping Illicit Small Arms Flows in Africa. Geneva: Small Arms Survey.

Smith R (2016) Military Economics: The Interaction of Power and Money. New York: Springer.

Smith R and Tasiran A (2010) Random coefficients models of arms imports. Economic Modelling 27(6): 1522-1528.

Smith RP and Tasiran A (2005) The demand for arms imports. Journal of Peace Research 42(2): $167-181$.

Sprague O (2006) UN Arms Embargoes: An Overview of the Last Ten Years. London: Oxfam International.

Starr H and Most BA (1978) A return journey: Richardson, "frontiers," and wars in the 1946-1965 era. Journal of Conflict Resolution 22(3): 441-467.

Stinnett DM, Tir J, Diehl PF, et al. (2002) The correlates of war (cow) project direct contiguity data, version 3.0. Conflict Management and Peace Science 19(2): 59-67.

Stohl RJ (2005) Fighting the illicit trafficking of small arms. Review of International Affairs 25(1): 59-68.

Thurner PW, Schmid CS, Cranmer SJ, et al. (2019) Network interdependencies and the evolution of the international arms trade. Journal of Conflict Resolution 63(7): 1736-1764.

UNIDIR (2006) Developing a Mechanism to Prevent Illicit Brokering in Small Arms and Light Weapons: Scope and Implications, volume UNIDIR/2006/23. Geneva: United Nations Institute for Disarmament Research.

United Nations Security Council (2018) Resolution 2428. Security Council Report, (S/RES/2428).

\section{Author biographies}

Vincenzo Bove obtained his PhD in Economics at Birkbeck College London in 2011. He is currently Professor of Political Science at the University of Warwick.

Tobias Böhmelt obtained his PhD in International Relations from the University of Essex in 2010. $\mathrm{He}$ is currently Professor of Government at the University of Essex 